\title{
Minerais em melados e em caldos de cana
}

\author{
Minerals in sugar cane syrup and cane juice
}

\author{
Fernanda dos Santos NOGUEIRA ${ }^{1 *}$, Karla Silva FERREIRA², \\ Josil de Barros CARNEIRO JUNIOR ${ }^{3}$, Luís César PASSONI ${ }^{4}$
}

\section{Resumo}

A cana-de-açúcar está entre as culturas que apresenta larga escala de adaptações às condições climáticas, sendo utilizada para a fabricação de diversos produtos. Dentre os produtos derivados da cana-de-açúcar, o melado é tido popularmente como um alimento rico em ferro. Este trabalho objetivou conhecer a concentração de alguns minerais em melados comerciais e em melados preparados com equipamentos de aço inoxidável. Ao todo foram 20 amostras, 10 de cada tipo. As amostras foram preparadas para análise por oxidação da matéria orgânica por via úmida e os teores de $\mathrm{Ca}, \mathrm{Mg}, \mathrm{Cu}, \mathrm{Mn}, \mathrm{Zn}$ e Fe foram determinados por espectroscopia de absorção atômica, Na e K por fotometria de chama e P por colorimetria. Concluiu-se, com este trabalho, que os teores médios dos minerais Fe, $\mathrm{P}, \mathrm{Na}$ e $\mathrm{Mg}$ foram significativamente mais elevados nos melados comerciais do que nos melados feitos com equipamentos inox. O contrário foi encontrado para o mineral cálcio, que apresentou teor mais elevado nos melados feitos no laboratório, mas condizentes com os teores encontrados nos caldos de cana. Não houve diferença significativa nos teores dos demais minerais.

Palavras-chave: valor nutritivo de alimentos; composição química de alimento; bebida.

\begin{abstract}
Sugar cane is an easily adaptable crop to diverse climate conditions, and it is used in the manufacturing of many different products. Among those products is the syrup, which is popularly known to be good sources of iron. In this work, we aimed to measure the concentration of some minerals in commercial sugar cane syrup brands and syrup prepared in the laboratory using stainless steel equipment. A total of 20 samples were analyzed, 10 of commercial brands and ten prepared in the laboratory. The samples were prepared by wet-air oxidation of organic matter and the contents of $\mathrm{Ca}, \mathrm{Mg}, \mathrm{Cu}, \mathrm{Mn}, \mathrm{Zn}$, and Fe were determined by atomic absorption. $\mathrm{Na}$ and $\mathrm{K}$ were determined by photometry and $\mathrm{P}$ by colorimetry. It was found that the mean concentration of $\mathrm{Fe}, \mathrm{P}, \mathrm{Na}$, and Mn were higher in the commercial products than in that prepared in the laboratory using stainless steel equipment. On the other hand, it was found that the calcium content was higher in the laboratory made syrup, which is in agreement with the Ca content found for the sugarcane juice. There was no significant difference in the concentration of the other tested minerals.
\end{abstract}

Keywords: foods nutrition facts; foods chemical composition; beverage.

\section{Introdução}

O Brasil é o maior produtor de cana-de-açúcar do mundo. Em 2003, a área ocupada com plantações de cana-de-açúcar foi de 5,3 milhões de hectares, dos quais 3,3 milhões na região Sudeste. Neste período foram plantados 161.850 ha no Estado do Rio de Janeiro, tendo a região Norte Fluminense 91\% de toda a área plantada do Estado, aproximadamente, 147.285 ha (IBGE, 2005)

O valor nutricional da cana está diretamente ligado ao seu alto teor de açúcar ( 40 a 50\% de açúcares na matéria seca), uma vez que o seu conteúdo proteico é extremamente baixo, o que lhe confere a característica de ser um alimento muito desbalanceado em relação a seus nutrientes. A cana é uma planta composta, em média, de 65 a 75\% de água, mas seu principal componente é a sacarose, que corresponde de 70 a $91 \%$ das substâncias sólidas solúveis. Caldo de cana ou garapa é o nome que se dá ao líquido extraído da cana-de-açúcar no processo de moagem. É um alimento muito energético, assim como a rapadura, que é feita através de processamento após a concentração do caldo. Do caldo de cana também são feitos melado e açúcar mascavo. O caldo conserva todos os nutrientes da cana-de-açúcar, entre eles minerais (de 3 a 5\%) como ferro, cálcio, potássio, sódio, fósforo, magnésio e cloro, além de vitaminas do complexo $\mathrm{B}$ e C (FAVA, 2004).

A composição dos alimentos pode variar em razão de diversos fatores. No caso da cana-de-açúcar, a deficiência de potássio acarreta menor teor de açúcar no colmo devido à função da ativação enzimática que este mineral possui, participando no transporte de carboidratos. A deficiência de cálcio pode ser

\section{Recebido para publicação em 22/11/2007}

Aceito para publicação em 8/7/2009 (003034)

${ }^{1}$ Universidade Aberta, Universidade Estadual do Norte Fluminense Darcy Ribeiro - UENF, Avenida Alberto Lâmego, 2000, CEP 28130-000, Parque Califórnia, Campos dos Goytacazes - RJ, E-mail: nandasnogueira@gmail.com

2 Universidade Estadual do Norte Fluminense Darcy Ribeiro - UENF, Avenida Alberto Lâmego, 2000, CEP 28130-000, Parque Califórnia, Campos dos Goytacazes - RJ, E-mail: karlasf@uenf.br

${ }^{3}$ Universidade Federal Rural do Rio de Janeiro - UFRRJ, Av. Pres. Vargas, 180, Campos dos Goytacazes - RJ, CEP 28053-100, E-mail: melhoramento_clm@yahoo.com.br

${ }^{4}$ Universidade Estadual do Norte Fluminense Darcy Ribeiro - UENF, Avenida Alberto Lâmego, 2000, CEP 28130-000, Parque Califórnia, Campos dos Goytacazes - RJ,

E-mail: lpassoni@uenf.br

${ }^{*}$ A quem a correspondência deve ser enviada 
causada pelo uso de vinhaça, na qual o teor de potássio é muito elevado, competindo então pela absorção do cálcio (VITTI et al., 2005). Maior disponibilidade de cobre ocorre em solos com pH entre 5,0 e 6,5. Em solos orgânicos, apesar de ricos em cobre, este mineral apresenta-se menos disponível. Além disso, elevadas concentrações de ferro, alumínio e manganês reduzem a disponibilidade de cobre para a planta. $\mathrm{O}$ ferro se encontra mais disponível para a cana em solos com $\mathrm{pH}$ entre 4,0 e 6,0. A deficiência de ferro, na maioria das vezes, é causada por desequilíbrio na relação a outros metais tais como cobre, molibdênio, manganês e excesso de fósforo, calagem excessiva etc. Há formação de complexos mais estáveis, entre a matéria orgânica e o manganês, quando o pH do solo se encontra entre pH 5 e 6,5. Um fato que interfere na formação desse complexo é a taxa de umidade do solo. Excesso de ferro, magnésio e cálcio também podem causar deficiência de manganês. A faixa de $\mathrm{pH}$ do solo que favorece a disponibilidade do zinco é entre $\mathrm{pH}$ 5,0 e 6,5. A deficiência ocorre com valores de $\mathrm{pH}$ superiores a 6,0 (LOPES; CARVALHO, 1988, apud VITTI et al., 2005).

O melado é popularmente indicado como fonte de ferro. De fato, segundo Tabela Brasileira de Composição de Alimento (NEPA/UNICAMP, 2006), o teor de ferro em melado é de $5,4 \mathrm{mg} .100 \mathrm{~g}^{-1}$ de produto, o que corresponde a $39 \%$ do valor recomendado, segundo a RDC n 360 de 23 de dezembro de 2003 (BRASIL, 2003b).

O ferro é um mineral muito bem conservado pelo organismo: cerca de $90 \%$ é recuperado e reutilizado frequentemente. Embora esteja presente no corpo humano em quantidades pequenas, suas funções são essenciais à vida. Apesar de fazer parte de diversas enzimas, sua função mais conhecida é na constituição das células vermelhas do sangue. A deficiência crônica deste mineral causa a anemia, com redução do número de células vermelhas e, consequentemente, diminuição da oxigenação das células do corpo (LEHNINGER et al., 2002).

Ao contrário do que ocorre com alguns compostos orgânicos, que podem ser destruídos durante a cocção dos alimentos, com a maioria dos minerais isso não acontece. Sua concentração no produto final pode ser até maior, caso haja concentração da matéria-prima, como ocorre na fabricação do melado. Por outro lado, a presença de minerais nos alimentos pode ser devido à contaminação durante o cultivo e processamento. Na obtenção do caldo de cana para fabricação de melado, não é comum o uso de equipamentos de aço inoxidável, o que pode acarretar contaminação do produto.

O objetivo deste trabalho foi determinar os teores de alguns minerais (cálcio, ferro, potássio, fósforo, sódio, cobre, magnésio, zinco, manganês) em melados comerciais e melados feitos com caldos de canas moídos e concentrados em equipamentos de aço inoxidável.

\section{Material e métodos}

\subsection{Amostras}

Foram analisadas 20 amostras de melados e 16 amostras de caldo de cana. Dez amostras de melado foram adquiridas por meio de compra em supermercados da Região Norte
Fluminense. Das amostras de caldo de cana, duas foram moídas na propriedade rural e 14 foram moídas em moenda de inox. Dos caldos obtidos em moenda de inox, 10 foram utilizados para a fabricação de melado. Os caldos de cana foram obtidos de 14 variedades de canas de plantações do sul do Estado do Espírito Santo e norte do Estado do Rio de Janeiro (RB 947520, RB 92596, RB 918639, RB 92579, RB928064, RB 931530, RB 855036, RB 835486, RB 92606, RB 791011, RB 867515, RB 72454, SP 801842).

\subsection{Fabricação do melado}

Cinco canas de cada variedade foram moídas em moenda de rolo inox. Do caldo total obtido, utilizou-se um litro para a fabricação do melado, usando-se panela de inox. O caldo foi aquecido até $60^{\circ} \mathrm{C}$, adicionou-se, aproximadamente, 0,75 g de ácido cítrico para a inversão da sacarose, misturou-se por 10 minutos para uma melhor homogeneidade do caldo com o ácido cítrico e, então, elevou-se a temperatura até fervura para concentração do caldo. O ponto final foi estabelecido quando o brix atingiu, aproximadamente, $83^{\circ}$, medido com refratômetro de bancada. Este valor foi escolhido porque foi o valor médio observado nos melados comerciais.

\subsection{Determinação de umidade}

A determinação da porcentagem de umidade dos melados foi feita em estufa a vácuo e temperatura de $70^{\circ} \mathrm{C}$, adicionandose areia calcinada para evitar que a amostra espirrasse e aumentasse a superfície de contato.

\subsection{Preparo das amostras para análise dos minerais}

As amostras foram preparadas por meio de oxidação da matéria orgânica por via úmida (CUNNIFF, 1998). Peso exato, em torno de $1,0 \mathrm{~g}$ de melado e $10 \mathrm{~mL}$ de caldo de cana, foi colocado em erlenmeyer de $125 \mathrm{~mL}$. A seguir, foram adicionados $15 \mathrm{~mL}$ de $\mathrm{HNO}_{3}$ e $1 \mathrm{~mL}$ de $\mathrm{HCLO}_{4}$. Os erlenmeyers foram levados a chapas de aquecimento, observando-se inicialmente eliminação de fumaça marrom, devido à degradação da matéria orgânica, e na fase final, eliminação de fumaça branca, devido à evaporação dos ácidos utilizados, confirmando toda a eliminação da matéria orgânica. As amostras foram diluídas para $50 \mathrm{~mL}$ com água desionizada.

Os teores de ferro, cobre, magnésio, manganês, zinco e cálcio foram determinados por meio de espectroscopia de absorção atômica, sódio e potássio por fotometria de chamas e o fósforo por colorimetria, após complexação com molibdato de amônio (CUNNIFF, 1998).

Todas as vidrarias utilizadas foram lavadas com detergente, enxaguadas e deixadas de molho em solução de $\mathrm{HCl} 0,1 \mathrm{~N}$ durante, pelo menos, 1 noite e novamente enxaguadas com água desionizada.

\subsection{Validação dos métodos}

A validação das análises foi feita pela adição de padrão. Em uma amostra previamente analisada adicionaram-se quantias 
correspondentes a 50, 100 e 150\% da concentração dos minerais ferro, potássio, sódio, magnésio, manganês e cobre. Os resultados mostraram taxa de recuperação numa faixa de 99 a $100 \%$.

\section{Resultados e discussão}

A Tabela 1 apresenta os teores de minerais encontrados nas amostras de melado. Os teores de ferro, fósforo, sódio e manganês foram significativamente mais elevados nos melados comerciais. Nas amostras de melados comerciais, as concentrações de ferro chegaram a ser de 3 a 8 vezes maiores que nos melados fabricados com caldos de cana-de-açúcar moídos em moinho inox. No caso do cobre, apesar de não apresentar diferença significativa, pode-se observar que a faixa de concentração atingiu valores mais elevados nos melados comerciais. Os teores mais elevados de ferro e alguns casos de cobre, nos melados comerciais, podem ser devido à contaminação durante a fabricação deste produto, desde a moenda até o tacho para a concentração do caldo que, em alguns casos, é de cobre. Este fato pode ser comprovado com uma variedade de cana produzida em localidades diferentes e da qual podem ser obtidas quatro amostras de caldo: duas produzidas e moídas nas diferentes propriedades e duas produzidas em cada uma destas propriedades, porém moídas em moendas de inox. Conforme se pode observar na Tabela 2, as faixas de variação dos teores de ferro, cobre e manganês foram mais elevadas nas amostras de caldo de cana moídas nas propriedades rurais do que as obtidas por moagem das canas em moinhos de inox. Seria interessante a análise de caldo de cana de todas as variedades, porém moídas também nas propriedades rurais, mas isso não foi possível.

Muitas moendas são de aço carbono, que é uma liga de ferro e carbono em que a porcentagem deste último é, geralmente, de apenas 0,1 a 1,0\%. Em certos aços especiais, o carbono pode chegar a 1,5\%. São também constituintes normais do aço o silício $(0,2 \%)$ e o manganês $(1,5 \%)$ (LIGAS METÁLICAS).

Considerando-se as faixas de concentrações de todos os minerais, apenas as do cálcio e magnésio foram superiores nos melados feitos no laboratório, mas a diferença foi significativa apenas para o cálcio. Este fato pode ser devido à calagem do solo onde estas canas foram cultivadas. É sabido que nem todos os agricultores corrigem o solo adequadamente e algumas variedades de cana utilizadas na fabricação dos melados com equipamentos de inox eram provenientes de canaviais devidamente adubados. Entretanto, os teores detectados nos melados feitos no laboratório são condizentes com os presentes nos caldos de cana (Tabela 2).

Considerando-se as faixas de variação nos teores dos minerais detectados nos melados comerciais, pode-se observar que foram similares aos publicados na Tabela Brasileira de Composição de Alimentos - TACO (NEPA/UNICAMP, 2006), exceto o sódio, cujos teores foram mais altos nos melados comerciais analisados neste trabalho, e o cálcio, cujos teores foram mais baixos. Por outro lado, nos melados feitos a partir de caldos de cana moídos em moenda de rolo inox, os teores de cálcio, potássio, magnésio, sódio e zinco foram similares aos apresentados na TACO. Já os teores de ferro, manganês, cobre e fósforo foram menores que os que constam na TACO. Segundo a TACO, o melado contém, por $100 \mathrm{~g}$ de produto, 5,4 mg de ferro, $395 \mathrm{mg}$ de potássio, $74 \mathrm{mg}$ de fósforo, 4,0 $\mathrm{mg}$ de sódio, 0,85 $\mathrm{mg}$ de cobre, $115 \mathrm{mg}$ de magnésio, $0,3 \mathrm{mg}$ de zinco, 2,6 mg de manganês e $102 \mathrm{mg}$ de cálcio. Estes valores constituem médias dos resultados analíticos de, no mínimo, 3 e, no máximo, 5 amostras das principais marcas comerciais dos produtos coletadas em super/hipermercados em diferentes regiões do País.

Melados feitos com caldos contendo teores iguais de determinado mineral podem apresentar teores diferentes deste mineral, mesmo que o brix ou o teor de umidade dos melados sejam semelhantes. Isso ocorre porque a concentração de cada caldo depende do teor de açúcar inicialmente presente nesse caldo. Na Tabela 3 são mostrados os valores médios e faixas de variação dos teores de umidade nos melados e caldos de cana. Entretanto, os teores de minerais no melado devem ser proporcionais aos do caldo. Na fabricação de melado, o caldo de cana é concentrado, aproximadamente, de 2,5 a 4 vezes, dependendo da quantidade de açúcar inicialmente presente no caldo. Este fato pode ser constatado com todos os minerais, quando são comparados os teores dos minerais nos caldos e nos melados feitos com os respectivos caldos. Por exemplo, o teor médio de ferro nos melados feitos foi $0,64 \mathrm{mg} .100 \mathrm{~g}^{-1}$, valor que é, aproximadamente, 3 vezes maior que o dos caldos, $0,22 \mathrm{mg} \cdot 100 \mathrm{~g}^{-1}$. Destacam-se os teores de cálcio nos melados elaborados em laboratório, que foram maiores do que os comerciais, porém condizentes com os teores encontrados nos caldos.

De acordo com a RDC n ${ }^{\circ} 27$ de 13 de janeiro de 1998 (BRASIL, 1998), um alimento pode receber a denominação de fonte de vitaminas ou minerais se contiver um mínimo de

Tabela 1. Teores de minerais em melados em mg.100 g-1 de amostra.

\begin{tabular}{lccccccccc}
\hline & $\mathrm{Fe}$ & $\mathrm{K}$ & $\mathrm{P}$ & $\mathrm{Na}$ & $\mathrm{Cu}$ & $\mathrm{Mg}$ & $\mathrm{Zn}$ & $\mathrm{Mn}$ & $\mathrm{Ca}$ \\
\hline $\mathrm{MMC}^{1}$ & $3,37^{\mathrm{a}}$ & $288^{\mathrm{a}}$ & $57^{\mathrm{a}}$ & $23,7^{\mathrm{a}}$ & $0,37^{\mathrm{a}}$ & $94^{\mathrm{a}}$ & $0,61^{\mathrm{a}}$ & $1,8^{\mathrm{a}}$ & $36^{\mathrm{a}}$ \\
$\mathrm{MMI}^{2}$ & $0,64^{\mathrm{b}}$ & $244^{\mathrm{a}}$ & $19^{\mathrm{b}}$ & $0,91^{\mathrm{b}}$ & $0,06^{\mathrm{a}}$ & $86^{\mathrm{a}}$ & $0,48^{\mathrm{a}}$ & $1,2^{\mathrm{b}}$ & $204^{\mathrm{b}}$ \\
$\mathrm{CV}^{3}$ & 79 & 68 & 79 & 117 & 235 & 44 & 52 & 37 & 40 \\
$\mathrm{FV} \mathrm{MC}^{4}$ & 1,2 a 7,5 & 62 a 699 & 4,6 a 155 & 4,6 a 57 & 0,04 a 2,4 & 18 a 139 & 0,31 a 1,59 & 0,39 a 2,8 & 22 a 50 \\
$\mathrm{FV} \mathrm{MI}^{5}$ & 0,4 a 0,9 & 61 a 469 & 4,3 a 26 & 0 a 4,6 & 0,04 a 0,07 & 33 a 163 & 0,34 a 0,69 & 0,76 a 1,64 & 111 a 306 \\
\hline
\end{tabular}

${ }^{*}$ Médias seguidas pela mesma letra, na coluna, não diferem entre si pelo teste de Tukey ( $\mathrm{p} \geq 0,05$ ); ${ }^{1} \mathrm{MMC}$ : média dos teores de minerais em 10 amostras de melados Comerciais; ${ }^{2} \mathrm{MMI}$ : média dos teores de minerais em 10 amostras de melados feitos com equipamentos de inox; ${ }^{3} \mathrm{CV}$ : coeficiente de variação; ${ }^{4} \mathrm{FVMC}$ : faixa de variação dos teores de minerais nos melados comerciais; $\mathrm{e}^{5} \mathrm{FVMI}$ : faixa de variação dos teores de minerais nos melados feitos com equipamentos de inox. 
Tabela 2. Teores de minerais em caldos de cana em mg.100 $\mathrm{mL}^{-1}$ de caldo.

\begin{tabular}{lccccccccc}
\hline & $\mathrm{Fe}$ & $\mathrm{K}$ & $\mathrm{P}$ & $\mathrm{Na}$ & $\mathrm{Cu}$ & $\mathrm{Mg}$ & $\mathrm{Zn}$ & $\mathrm{Mn}$ & $\mathrm{Ca}$ \\
\hline $\mathrm{CMP}^{1}$ & 2,3 & 7,1 & 1,9 & 0 & 0,45 & 12 & 0,14 & 0,63 & 31 \\
$\mathrm{CMI}^{2}$ & 0,12 & 27 & 1,1 & 0 & 0,02 & 9,4 & 0,06 & 0,25 \\
$\mathrm{CMP}^{3}$ & 2,9 & 42 & 3,7 & 0,45 & 0,04 & 17 & 0,11 & 0,54 \\
$\mathrm{CMI}^{4}$ & 0,06 & 17 & 1,4 & 0 & 0,03 & 12 & 0,09 & 0,41 & 28 \\
$\mathrm{MCMI}^{5}$ & 0,22 & 63 & 5,2 & 0 & 0,02 & 25 & 0,14 & 0,34 & 21 \\
$\mathrm{CV} \mathrm{CMI}^{6}$ & 31 & 45 & 50 & 0 & 0 & 42 & 29 & 21 & 39 \\
$\mathrm{FV} \mathrm{CMI}^{7}$ & 0,12 a 0,31 & 17 a 115 & $1,1 \mathrm{a} 10$ & 0 & $0,01 \mathrm{a} 0,03$ & $9,4 \mathrm{a} 48$ & 0,06 a 0,22 & $0,21 \mathrm{a} 0,44$ & $15 \mathrm{a} 79^{-1}$
\end{tabular}

${ }^{1}$ CMP1: caldo de cana, variedade RB 72454, cultivada e moída na propriedade 1 - Espírito Santo; ${ }^{2} \mathrm{CMI1}$ : caldo de cana, variedade RB 72454, cultivada na propriedade 1, mas moída em moenda de rolo inox; ${ }^{3} \mathrm{CMP} 2$ : caldo de cana, variedade RB 72454, cultivada e moída na propriedade 2 - Rio de Janeiro; ${ }^{4} \mathrm{CMI} 2$ : caldo de cana, variedade RB 72454 , cultivada na propriedade 2, mas moída em moenda de rolo inox; ${ }^{5} \mathrm{MCMI}$ : média dos teores de minerais em 14 amostras de caldos de cana moída em moenda de rolo inox; ${ }^{6} \mathrm{CV}$ CMI: coeficiente de variação dos caldos de cana moída em moenda de rolo inox; e ${ }^{7} \mathrm{FV}$ CMI: faixa de variação dos caldos de cana moída em moenda de rolo inox.

Tabela 3. Porcentagem de umidade nos melados e nos caldos de cana.

\begin{tabular}{|c|c|c|}
\hline & Média & Faixa de variação \\
\hline Melados comerciais $^{(10)}$ & 18 & 11 a 25 \\
\hline $\begin{array}{l}\text { Melados feitos com canas moídas em } \\
\text { moenda de rolo inox }^{(10)}\end{array}$ & 17 & 13 a 21 \\
\hline Caldos de Cana ${ }^{(16)}$ & 77 & 74 a 82 \\
\hline
\end{tabular}

('Número de amostras entre parênteses.

$15 \%$ da ingestão diária recomendada do respectivo nutriente em 100 g, no caso de alimentos sólidos, ou um mínimo de 7,5\% em $100 \mathrm{~mL}$, no caso de alimentos líquidos. Ao serem estabelecidos estes limites, foi considerada a quantidade possível de ser ingerida dos alimentos. Usualmente, os alimentos líquidos podem ser ingeridos em maior quantidade. No caso do melado, a quantidade possível de ser ingerida é menor que a maioria dos alimentos sólidos, sendo considerada a porção de $20 \mathrm{~g}$ (BRASIL, 2003a). Sendo assim, os melados comerciais poderiam ser classificados como fonte de ferro, cobre e manganês, ao passo que os elaborados com equipamentos de inox poderiam ser classificados como fontes de cálcio, manganês e magnésio. Deve-se considerar que os teores destes elementos podem ser mais baixos em razão de características do solo, variedade da cana e adubação do canavial, conforme observado nos caldos de cana.

Como mencionado no início do trabalho, popularmente o melado é indicado como fonte de ferro. Sendo um produto de origem vegetal ou proveniente de contaminação e submetido ao calor, provavelmente o ferro encontra-se na forma oxidada $\left(\mathrm{Fe}^{3+}\right)$, o que implica em péssima ou nenhuma absorção (SILVA; WILLIAMS, 1993). Segundo este mesmo autor, a passagem dos íons através das membranas celulares é inversamente proporcional às suas cargas, por este motivo, os minerais com nox \pm 1 são os de absorção mais rápida, ao passo que os com nox \pm 3 e \pm 4 podem nem ser absorvidos.

\section{Conclusões}

Nos melados comerciais, os teores médios de ferro (3,37 mg.100 g $\left.\mathrm{g}^{-1} \times 0,64 \mathrm{mg} .100 \mathrm{~g}^{-1}\right)$, fósforo $\left(57 \mathrm{mg} \cdot 100 \mathrm{~g}^{-1} \times\right.$ $\left.19 \mathrm{mg} .100 \mathrm{~g}^{-1}\right)$, sódio $\left(23,7 \mathrm{mg} .100 \mathrm{~g}^{-1} \times 0,91 \mathrm{mg} .100 \mathrm{~g}^{-1}\right)$ e manganês $\left(1,8 \mathrm{mg} .100 \mathrm{~g}^{-1} \times 1,2 \mathrm{mg} .100 \mathrm{~g}^{-1}\right)$ foram significativamente mais elevados que nos melados elaborados com equipamentos de aço inoxidável. Os teores de cálcio, ao contrário, foram maiores nos melados elaborados em laboratório (204 mg.100 g $\mathrm{g}^{-1} \times 36 \mathrm{mg} .100 \mathrm{~g}^{-1}$ ), mas condizentes com os teores encontrados nos caldos de cana. Apesar dos teores médios terem sido superiores nos melados comerciais, não foi detectada diferença significativa para o potássio $\left(288 \mathrm{mg} .100 \mathrm{~g}^{-1} \times 244 \mathrm{mg} .100 \mathrm{~g}^{-1}\right)$, cobre $\left(0,37 \mathrm{mg} .100 \mathrm{~g}^{-1} \times\right.$ $\left.0,06 \mathrm{mg} .100 \mathrm{~g}^{-1}\right)$ e zinco $\left(0,61 \mathrm{mg} \cdot 100 \mathrm{~g}^{-1} \times 0,48 \mathrm{mg} \cdot 100 \mathrm{~g}^{-1}\right)$. Os resultados deste trabalho dão indícios de que os equipamentos usados para extração de caldo e fabricação de melado comercial não estão de acordo com as exigências em relação às normas estabelecidas de higiene para a indústria de alimentos.

\section{Agradecimentos}

Ao Prof. Pedro Henrique Monnerat, ao Técnico José Accácio da Silva e à Valdinéia Estephaneli Pinto que possibilitaram a execução deste trabalho, e à Pró-Reitoria de Extensão da UENF pela concessão da bolsa de extensão.

\section{Referências bibliográficas}

BRASIL. Ministério da Saúde. Agência Nacional de Vigilância Sanitária. Resolução RDC 359 de 23 de dezembro de 2003. Regulamento técnico de porções de alimentos embalados para fins de rotulagem nutricional. Brasília. Diário Oficial da União, Brasília, 26 de dezembro de 2003a. Disponível em: <www.anvisa.gov.br $>$. Acesso em: 9 Novembro 2007.

BRASIL. Ministério da Saúde. Agência Nacional de Vigilância Sanitária. Resolução RDC 360 de 23 de Dezembro de 2003. Regulamento técnico sobre rotulagem nutricional de alimentos embalados. Diário Oficial da União, Brasília, 26 de dezembro de 2003b. Disponível em:<www.anvisa.gov.br>. Acesso em: 25 Outubro 2007.

BRASIL. Ministério da Saúde. Agência Nacional de Vigilância Sanitária. Resolução RDC 27 de 13 de Janeiro de 2003. Regulamento Técnico sobre Informação Nutricional Complementar. Diário Oficial da União, Brasília, 16 de janeiro de 1998. Disponível em: <www.anvisa. gov.br>. Acesso em: 5 Novembro 2007.

CUNNIFF, P. Official methos of analysis of aoac international. $4 \mathrm{ed}$. Maryland: AOAC International, 1998. Volume I, p. 1-8, 9, 31-34.

FAVA, A. R. Atletas ingerem garapa para repor energia. Jornal da Unicamp, edição 250, de 3 a 9 de Maio de 2004. Disponível 
em: <www.unicamp.br/unicamp/unicamp_hoje/ju/maio2004/ ju250pag8a.html>. Acesso em: 20 Outubro 2007.

INSTITUTO BRASILEIRO DE GEOGRAFIA E ESTATÍSTICA IBGE. 2005. Disponível em: <www.ibge.gov.br/home/estatistica/ calendario_estudos2005.shtm>. Acesso em: 10 Outubro 2007.

LEHNINGER, A. L.; NELSON, D. L.; COX, M. M. Lehninger princípios de bioquímica. 3 ed. São Paulo: SARVIER, 2002.

LIGAS metálicas - categoria química. Disponível em: <http:// br.answers.yahoo.com/question/index?qid=20071025182522AAo bgrH>. Acesso em: 28 Outubro 2007.
NÚCLEO DE ESTUDOS E PESQUISAS EM ALIMENTAÇÃO NEPA. Tabela Brasileira de Composição de Alimentos - TACO. Versão II. 2 ed. Campinas, SP: UNICAMP, 2006. 113 p. Disponível em: $<$ www.unicamp.br/nepa/taco/tabela.php?ativo=tabela $>$. Acesso em: 22 Outubro 2007.

SILVA, J. J. R. F.; WILLIAMS, R. J. P. The biological chemistry of the elements: the inorganic chemistry of life. New York: Oxford University Press, 1993. 561 p.

VITTI, G. D. et al. Nutrição e Adubação da Cana-de-açúcar. Bebedouro, SP: [s.n.], 2005. p. 15-18. 